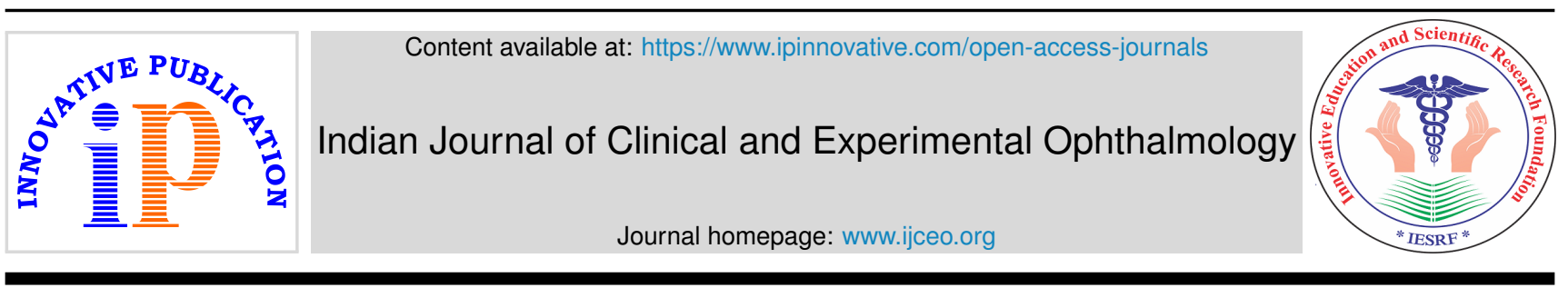

Original Research Article

\title{
Evaluation of knowledge, attitude and practice of guidelines towards the novel covid 19 among eye care professionals of a government medical college in north India
}

\author{
Aswathi Venugopal ${ }^{1}$,*, Sunil Kumar ${ }^{1}$, Sony Sinha ${ }^{1}$ \\ ${ }^{1}$ Dept. of Ophthalmology, Patna Medical College and Hospital, Patna, Bihar, India
}

\section{A R T I C L E I N F O}

\section{Article history:}

Received 18-01-2021

Accepted 25-01-2021

Available online 30-06-2021

Keywords:

Attitude

Covid- 19

Eye care professionals

Knowledge

Practice

\begin{abstract}
A B S T R A C T
Background: The novel COVID-19 pandemic, caused by the SARS CoV- 2 virus, has led to widespread public health concerns across the globe. Ophthalmology professionals may be susceptible to infection due to close patient proximity during slit lamp examination and the potential contamination of instruments. The knowledge, attitude, practice (KAP)study can provide an insight of ECPs'(eye care practitioners) knowledge, methods of practice and attitude during this pandemic. This helps to reduce their risk, and that of their family, of contracting the virus, reduce morbidity and mortality associated with being infected.Data and results obtained from this study can also be used to make emergency policies and implement them to stop the spread and impact of a similar outbreak in future.

Methods: A cross-sectional study was conducted to evaluate the knowledge, attitude and practice of guidelines amongst the Eye care professionals towards the novel Covid-19. The demographic characteristics and infection rate of Covid-19 among the professionals during practice was also recorded and analyzed.

Results: In this hospital based cross-sectional study, total 67 eye care professionals including nurses, optometrist participated in the study with their due consent. Among total 67 participants, 60 (89.5\%) were doctors, 4 (5.97\%) were nurses and 3 (4.477) were optometrists All the participants including doctors, nurses and optometrists achieved a mean of $97.8 \%$ in the knowledge section of questionnaire.100\% of the participants wear mask and maintain social distancing while all of them have received training regarding practice and management of patients during Covid19 and all the participants have a positive attitude towards the measure taken to combat Covid-19 pandemic.

Conclusion: The eye care professionals participated in this study shows a good knowledge, positive attitude and practice of guidelines by the government of India are followed for the pandemic of Covid-19.

(C) This is an open access article distributed under the terms of the Creative Commons Attribution License (https://creativecommons.org/licenses/by/4.0/) which permits unrestricted use, distribution, and reproduction in any medium, provided the original author and source are credited.
\end{abstract}

\section{Introduction}

The novel COVID-19 pandemic, caused by the SARS CoV- 2 virus, a member of the beta corona virus genus, has led to widespread public health concerns across the globe. ${ }^{1}$ The emergence of the novel corona virus disease (COVID-19) in December 2019 in the city of Wuhan, the Chinese province of Hubei city, halted the ever-busy human society and caused serious threat to all sectors

\footnotetext{
* Corresponding author.

E-mail address: aswathivenugopa125@gmail.com (A. Venugopal).
}

of every nation. ${ }^{2}$ It is related to Middle East respiratory syndrome corona virus (MERS- $\mathrm{CoV}$ ) and severe acute respiratory syndrome corona virus (SARS-CoV). ${ }^{3}$ The infection soon became a cause of concern with the World Health Organization, declaring the rapid spread of cases of COVID-19 a pandemic on 11th March, 2020 and recommended that a globally coordinated effort was needed to fight the pandemic. ${ }^{4}$ The first SARS-CoV-2 positive case in India was reported in the state of Kerala on January 30th, 2020. Subsequently, the number of cases drastically rose. According to the press release by the Indian Council 
of Medical Research (ICMR) on May 8th, 2020, a total of $14,37,788$ suspected samples had been sent to the National Institute of Virology (NIV), Pune, and a related testing laboratory. ${ }^{5}$

COVID-19 initially presents as fever, cough, dyspnoea, fatigue and myalgias; the clinical course may remain mild but those with co morbidities and compromised immune system may be associated with need for ventilator support and high overall mortality. ${ }^{6}$ COVID-19 is characterized by rapid transmission, and can occur by close interaction with an infected person. ${ }^{7}$ There are also reports of conjunctivitis and transmission of the virus by aerosol contact with conjunctiva with some uncertainty as to whether the virus is evident in human tears. ${ }^{8}$ Ocular manifestations have also been reported in COVID-19, and have been purported by some to be the earliest sign of the disease in symptomatic individuals. ${ }^{5}$ Previously other respiratory viruses, especially influenza, have been shown to use the eye as a portal of entry, with the H7 subtype having a particular ocular tropism. ${ }^{2}$ The risk of death in COVID- 19-infected individuals increases with older age, presence of hypertension, diabetes and coronary heart diseases. ${ }^{2}$ Ophthalmology practitioners may be susceptible to infection due to close patient proximity during slit lamp examination and the potential contamination of instruments. ${ }^{6}$

If eye care professionals(ECP) limited operations during the lockdown - particularly those in need of emergency care or receiving routine injections for management of blinding eye diseases such as diabetes macular edema probably would have underwent adverse effect over vision and future prognosis of the people under routine eye care. ECPs may be susceptible to infection due to close patient proximity during examination. ${ }^{7}$

The aim of this study was to assess knowledge, attitude and practice of guidelines of COVID-19 exposure risk among ECPs as well as understand their confidence in current Ministry of Health $(\mathrm{MoH})$ guidelines for identifying possible COVID-19 cases, knowledge of Personal Protective Equipment (PPE) recommendations and training in its usage when managing such cases. The impact of COVID-19 lockdown among practitioners was also assessed. The findings have provided an insight of ECPs' knowledge of COVID-19. This helps to reduce their risk, and that of their family, of contracting the virus, reduce morbidity and mortality associated with being infected. Evidence from the study can also be used to implement emergency policies to counter the spread and impact of a similar outbreak in future. The study will provide clarity on the essential nature of ECPs services to help policy making in future outbreaks

\section{Materials and Methods}

Institutional ethical committee approval was obtained before commencement of study.

A cross sectional study was conducted to evaluate the Knowledge attitude and practice of guidelines amongst the different grades of prescribers towards the novel Covid 19.

Study was conducted at a Government medical college and a tertiary care hospital in north India for a period of two months (Oct 1st-Nov, 30th 2020)

\subsection{Inclusion \& exclusion criteria}

Eye care practitioners (faculty consultants, medical officers, post graduate students, optometrist and nurses) working in the medical college hospital have been enrolled in the study after obtaining an informed consent. The health professionals who did not want to give was excluded from the study.

A list of different grade of eye care practitioners was prepared with the help of establishment section (human resource department) of the government teaching Hospital and all the subjects fulfilling inclusion criteria were included in the study.

For the purpose of the study, a knowledge, attitude, practice(KAP) questionnaire was used. This questionnaire was used using the precedence set by similar studies. ${ }^{1,2,5,6}$ This questionnaire contains a total of 31 questions. Among the questions 15 are related to knowledge, 7 are related with attitude and 9 are related with practice of guidelines(Figure 1). Except for question no 6 rest of the questions to assess attitude of participants were collected mainly on the basis of likert scale. All questions were compulsory and subjects were asked not to disclose their identity. Every subject was given 30 minutes to fill up the questionnaire. Any clarification needed in understanding the questionnaire was provided.

The filled questionnaires were analyzed as per the study objectives. The various parameters such as 'sex distribution', 'age distribution', 'professional status', 'worksite', and the 'knowledge, attitude and practice of guideline scores' was analyzed. The data obtained was entered and analyzed in Microsoft excel spread sheet. SPSS was used to conduct the descriptive statistics. Results are expressed as the means and standard deviations, medians and ranges or numbers and percentages and are compared among different subgroups of respondents. Categorical data between the study groups was compared using the chi-squared test or Fisher's exact test as appropriate. $\mathrm{P}<$ 0.05 was considered to be level of significance.

Assessment of knowledge, attitude, and practice of guidelines of Covid 19 among the eye care practitioners, especially from Northern part of India, where such type of studies are sparse, is very important. This type of study may help to reduce the risk and that of their family, of contracting 
the virus, reduce morbidity and mortality associated with being infected. Evidence from this study can also be used to implement emergency policies to counter the spread and impact of a similar outbreak in future.

\section{Results}

In this hospital based cross-sectional study, total 67 eye care practitioners including nurses participated in the study with their due consent. Among total 67 participants $60(89.5 \%)$ were doctors, 4(5.97\%) were nurses and 3 (4.477) were optometrist. Doctors who participated in the study belong to various designations like Professor $(n=2 ; 3.3 \%)$, Associate professor $(n=1 ; 1.66 \%)$, Assistant professor $(n=8 ; 13.33 \%)$, Senior resident $(n=10 ; 16.6 \%)$, Junior resident $(n=39 ; 65 \%)$.

Among the participants $n=47 \quad(78.33 \%)$ doctors, $\mathrm{n}=1(25 \%)$ nurse, $\mathrm{n}=2(66.67 \%)$ optometrist belongs to age group 20-40yrs, $n=11(18.33 \%$ ) doctors, $n=3(7.5 \%)$ nurses, $\mathrm{n}=1(3.3 \%)$ optometrist belongs to age group 40-60yrs and $\mathrm{n}=2(3.34 \%)$ doctors are aged more than 60 yrs. Majority of the participants were not infected by covid-19 in past $n=56(93.33 \%), n=4(6.67 \%)$ were covid-19 positive in past.

Table 1: Age wise distribution of participants

\begin{tabular}{lccc}
\hline & $\begin{array}{c}\text { Doctor } \\
(\mathbf{n = 6 0})\end{array}$ & Nurse $(\mathbf{n = 4})$ & $\begin{array}{c}\text { Optometrist } \\
(\mathbf{n = 3})\end{array}$ \\
$20-40$ & $47(78.33 \%)$ & $1(25 \%)$ & $2(66.67 \%)$ \\
$40-60$ & $11(18.33 \%)$ & $3(75 \%)$ & $1(33.33 \%)$ \\
$>60$ & $2(3.34 \%)$ & - & - \\
\hline
\end{tabular}

Table 2: Sex distribution of participants

\begin{tabular}{lccc}
\hline Doctor $(\mathbf{n}=60)$ & $\begin{array}{c}\text { Nurse } \\
(\mathbf{n = 4})\end{array}$ & $\begin{array}{c}\text { Optometrist } \\
(\mathbf{n}=\mathbf{3})\end{array}$ \\
Male & $30(50 \%)$ & 0 & $3(100 \%)$ \\
Female & $30(50 \%)$ & $4(100 \%)$ & 0 \\
\hline
\end{tabular}

Table 3: Covid - 19 infected in past

\begin{tabular}{lccc}
\hline & Doctor $(\mathbf{n = 6 0})$ & Nurse $(\mathbf{n = 4})$ & $\begin{array}{c}\text { Optometrist } \\
(\mathbf{n}=\mathbf{3})\end{array}$ \\
Yes & $4(6.67 \%)$ & - & - \\
No & $56(93.33 \%)$ & $4(100 \%)$ & $3(100 \%)$ \\
\hline
\end{tabular}

\subsection{Assessment of knowledge about Covid 19}

Knowledge about the Covid-19 pandemic and related guidelines among the participants was assessed by the knowledge questioners and the responses are shown in the Table 4. It shows the comparison of knowledge about Covid 19 between doctors, nurses and optometrist.

Figure 1 it is evident that the participants have good knowledge regarding question number 1,2,5,7-14 and regarding question no 3 , among doctors $n=57(95 \%)$ consider treatment for Covid 19 is symptomatic therapy, $\mathrm{n}=4(100 \%)$ nurses and $\mathrm{n}=3(100 \%)$ optometrists also consider symptomatic therapy for Covid 19. From Table 4 we can assess that from the response for question no4, $56(93.33 \%)$ doctors consider age group above 60 years is more dangerous for Covid19 and 4(6.67\%) doctors think age group below 15years is more dangerous for Covid19. $100 \%$ of the nurses and optometrists consider age group above 60 years is more dangerous for Covid-19. As a response to question no6,among doctors 55(91.67\%) consider diarrhoea is a symptom for Covid19. On assessing question no15, 50(83.33\%) doctors could correctly answer about the ophthalmic emergency symptoms laid by the government of India and n-10(16.67\%) doctors were wrong about the guideline and $100 \%$ of the nurses $(n=4)$ and $100 \%$ of optometrist $(n=3)$ were correct about the guidelines.

\subsection{Assessment of attitude about Novel Covid 19 among eye care practitioners}

Assessment of attitude among eye care practitioners were assessed by 7 questions from the questionnaire on the basis of a five pointer likert scale except question no6. Responses are shown in Table 5.

Among 67 participants $n=60(100 \%)$ doctors, $n=4(100 \%)$ nurses and n-3(100\%) optometrist strongly agree to the fact that patients coming to Ophthalmology department must undergo detailed screening for Covid 19. From question no 2 it can be assessed that $n=50(83.33 \%)$ doctors and $100 \%$ of nurses and optometrist strongly agree that self monitoring of health and reporting it to state/district helpline should be followed by all whereas $n=10(16.67 \%)$ doctors agree to this. Regarding the encouragement of practice of Telecounselling and Tele-consultation, $\mathrm{N}=51(85 \%)$ of doctors and $100 \%$ of nurses and optometrist strongly agree and $\mathrm{n}=9(15 \%)$ of doctors agree to this. From question no 7 it can be assessed than $n=20(33.33 \%)$ doctors, $n=1(25 \%)$ nurse $\& n=1(33.33 \%)$ strongly agree to measures adopted by ministry of health in India to combat Covid 19, $\mathrm{n}=40(66.67 \%)$ doctors $\mathrm{n}=3(75 \%)$ nurses \& $\mathrm{n}=2(66.67 \%)$ optometrist agree to this.

\subsection{Assessment of practice of guidelines regarding Novel Covid 19 among eye care practitioners}

From this study it is evident that majority of eye care practitioners follow the guidelines meticulously. $100 \%$ of the participants wear mask, maintain social distancing while practice also all of them have received training regarding practice and management of patients during Covid19. All the participants in the study practice proper disposal of mask/gloves/face covers also practice regular cleaning and disinfection of instruments. Regarding display of posters/standees on preventive measures $n=1(67 \%)$ of doctors responded no and all other participants responded 
Table 4: Assessment of knowledge questions

\begin{tabular}{|c|c|c|c|c|c|c|c|}
\hline & \multicolumn{2}{|c|}{ Doctor $(n=60)$} & \multicolumn{2}{|c|}{ Nurse $(n=4)$} & \multicolumn{2}{|l|}{ Optometrist $(n=3)$} & \multirow{2}{*}{$\begin{array}{c}\text { Significance } \\
\text { P Value }\end{array}$} \\
\hline & Correct & Wrong & Correct & Wrong & Correct & Wrong & \\
\hline Qn 1 & $60(100 \%)$ & $0(0 \%)$ & $4(100 \%)$ & $0(0 \%)$ & $3(100 \%)$ & $(0 \%)$ & \\
\hline Qn 2 & $60(100 \%)$ & $0(0 \%)$ & $4(100 \%)$ & $0(0 \%)$ & $3(100 \%)$ & $(0 \%)$ & \\
\hline Qn 3 & $57(95 \%)$ & $3(5 \%)$ & $4(100 \%)$ & $0(0 \%)$ & $3(100 \%)$ & $(0 \%)$ & 0.83 \\
\hline Qn 4 & $56(93.33 \%)$ & $4(6.67 \%)$ & $4(100 \%)$ & $0(0 \%)$ & $3(100 \%)$ & $0(0 \%)$ & 0.78 \\
\hline Qn 5 & $60(100 \%)$ & $0(0 \%)$ & $4(100 \%)$ & $0(0 \%)$ & $3(100 \%)$ & $(0 \%)$ & \\
\hline Qn 6 & $55(91.67 \%)$ & $5(8.33 \%)$ & $4(100 \%)$ & $0(0 \%)$ & $3(100 \%)$ & $(0 \%)$ & 0.72 \\
\hline Qn 7 & $60(100 \%)$ & $0(0 \%)$ & $4(100 \%)$ & $0(0 \%)$ & $3(100 \%)$ & $(0 \%)$ & \\
\hline Qn 8 & $60(100 \%)$ & $0(0 \%)$ & $4(100 \%)$ & $0(0 \%)$ & $3(100 \%)$ & $(0 \%)$ & \\
\hline Qn 9 & $60(100 \%)$ & $0(0 \%)$ & $4(100 \%)$ & $0(0 \%)$ & $3(100 \%)$ & $(0 \%)$ & \\
\hline Qn 10 & $60(100 \%)$ & $0(0 \%)$ & $4(100 \%)$ & $0(0 \%)$ & $3(100 \%)$ & $(0 \%)$ & \\
\hline Qn 11 & $60(100 \%)$ & $0(0 \%)$ & $4(100 \%)$ & $0(0 \%)$ & $3(100 \%)$ & $(0 \%)$ & \\
\hline Qn 12 & $60(100 \%)$ & $0(0 \%)$ & $4(100 \%)$ & $0(0 \%)$ & $3(100 \%)$ & $(0 \%)$ & \\
\hline Qn 13 & $60(100 \%)$ & $0(0 \%)$ & $4(100 \%)$ & $0(0 \%)$ & $3(100 \%)$ & $(0 \%)$ & \\
\hline Qn 14 & $60(100 \%)$ & $0(0 \%)$ & $4(100 \%)$ & $0(0 \%)$ & $3(100 \%)$ & $(0 \%)$ & \\
\hline Qn 15 & $50(83.33 \%)$ & $10(16.67 \%)$ & $4(100 \%)$ & $0(0 \%)$ & $3(100 \%)$ & $(0 \%)$ & 0.50 \\
\hline
\end{tabular}

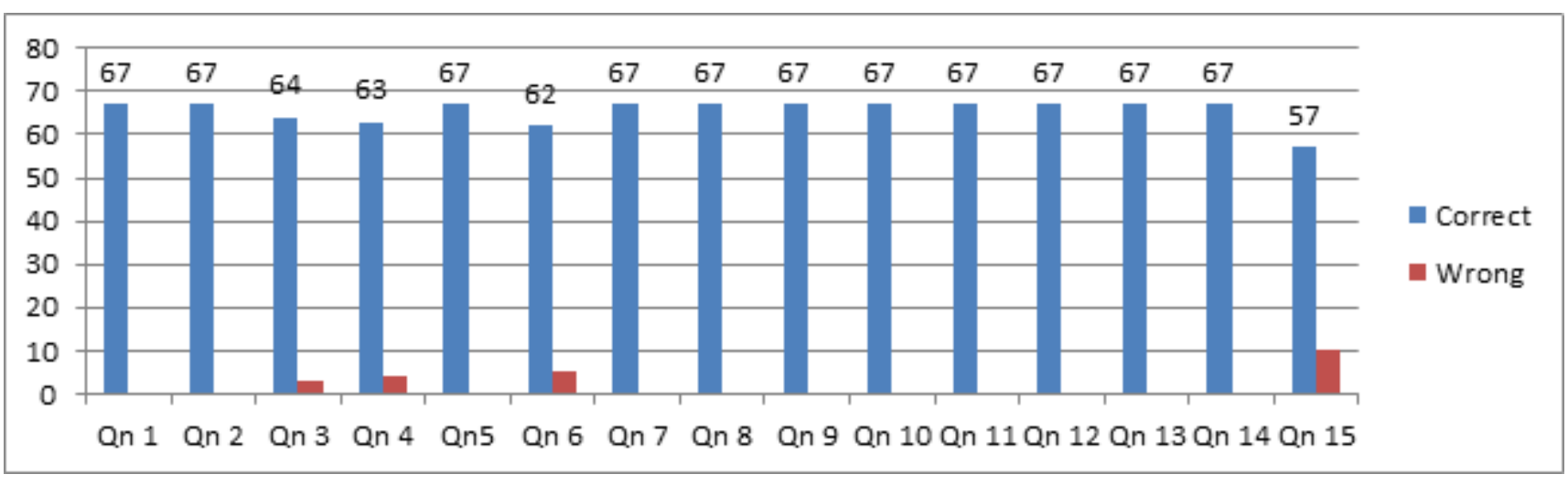

Fig. 1: Assessment of knowledge towards novel Covid 19 among eye care practitioners

yes, similar response was obtained for practice of guidelines of CPWD(central public works department) regarding airconditioning/ventilation guidelines.

\section{Discussion}

The novel COVID-19 pandemic, caused by the SARS CoV2 virus, a member of the beta corona virus genus, has led to serious concerns regarding public health, way of practice of healthcare system across the globe. ${ }^{1}$

After extensive literature search it was evident that studies related to assessment of knowledge, attitude, and practice of guidelines of Covid 19 among the eye care practitioners, are sparse especially in Northern parts of India. This type of study may help to reduce the risk of healthcare practitioners and that of their family, of contracting the virus, reduce morbidity and mortality associated with being infected. It is to be mentioned that 4 doctors among 67(5.97\%) participants was infected with Covid 19. Evidence from this study can also be used to implement emergency policies to counter the spread and impact of a similar outbreak in future.

Our findings suggests that most of the study participants were having good knowledge regarding the Novel Covid19. All the participants including doctors, nurses and optometrist achieved a mean of $97.8 \%$ in the knowledge section of questionnaire. This is similar to the results obtained by certain studiesconducted in Nigeria. Saudi Arabia \& Iran. ${ }^{2,5} 100 \%$ of the participants had knowledge regarding the causative agent and incubation period of the disease and $n=64(95.5 \%)$ of the participants knew that treatment for Covid-19 is symptomatic. The reason for attaining a good knowledge is probably due to the recent pandemic of Covid-19 and the awareness provided by government, media, seminars and other awareness and training programs. Also the academic background of the participants may have contributed to this fact which is similar to studies such as Nigeria, Saudi, Iran. Regarding inclusion of diarrhea or constipation as a symptom of Covid$19, \mathrm{n}=55(91.67 \%)$ of doctors considered it as true while $100 \%$ of the optometrist and nurses considered it as a 
Table 5: Assessment of attitude questions

\begin{tabular}{|c|c|c|c|c|c|c|c|}
\hline & & $\begin{array}{c}\text { Strongly } \\
\text { Agree / True }\end{array}$ & Agree & $\begin{array}{l}\text { Do not Know / } \\
\text { No Opinion }\end{array}$ & $\begin{array}{l}\text { Disagree / } \\
\text { False }\end{array}$ & $\begin{array}{l}\text { Strongly } \\
\text { Disagree }\end{array}$ & Wrong \\
\hline & Doctors $(n=60)$ & $60(100 \%)$ & - & - & - & - & - \\
\hline \multirow[t]{3}{*}{ Qn 1} & Nurse $(n=4)$ & $4(100 \%)$ & - & - & - & - & - \\
\hline & $\begin{array}{l}\text { Optometrician } \\
(\mathrm{n}=3)\end{array}$ & $3(100 \%)$ & - & - & - & - & \\
\hline & Doctors $(n=60)$ & $50(83.33 \%)$ & $10(16.67 \%)$ & - & - & - & - \\
\hline \multirow[t]{3}{*}{ Qn 2} & Nurse $(n=4)$ & $4(100 \%)$ & - & - & - & - & - \\
\hline & $\begin{array}{l}\text { Optometrician } \\
(\mathrm{n}=3)\end{array}$ & $3(100 \%)$ & - & - & - & - & - \\
\hline & Doctors $(n=60)$ & $51(85 \%)$ & $9(15 \%)$ & - & - & - & - \\
\hline \multirow[t]{3}{*}{ Qn 3} & Nurse $(n=4)$ & $4(100 \%)$ & - & - & - & - & - \\
\hline & $\begin{array}{l}\text { Optometrician } \\
(\mathrm{n}=3)\end{array}$ & $3(100 \%)$ & - & - & - & - & - \\
\hline & Doctors $(n=60)$ & $60(100 \%)$ & - & - & - & - & - \\
\hline \multirow[t]{3}{*}{ Qn 4} & Nurse $(n=4)$ & $4(100 \%)$ & - & - & - & - & - \\
\hline & $\begin{array}{l}\text { Optometrician } \\
(\mathrm{n}=3)\end{array}$ & $3(100 \%)$ & - & - & - & - & \\
\hline & Doctors $(n=60)$ & $60(100 \%)$ & - & - & - & - & - \\
\hline \multirow[t]{3}{*}{ Qn 5} & Nurse $(n=4)$ & $4(100 \%)$ & - & - & - & - & - \\
\hline & $\begin{array}{l}\text { Optometrician } \\
(\mathrm{n}=3)\end{array}$ & $3(100 \%)$ & - & - & - & - & \\
\hline & Doctors $(n=60)$ & $59(98.33 \%)$ & - & $1(1.67 \%)$ & - & - & - \\
\hline \multirow[t]{3}{*}{ Qn 6} & Nurse $(n=4)$ & $4(100 \%)$ & - & - & - & - & - \\
\hline & $\begin{array}{l}\text { Optometrician } \\
(\mathrm{n}=3)\end{array}$ & $3(100 \%)$ & - & - & - & - & - \\
\hline & Doctors $(n=60)$ & $20(33.33 \%)$ & $40(66.67 \%)$ & - & - & - & - \\
\hline \multirow[t]{2}{*}{ Qn 7} & Nurse $(n=4)$ & $1(25 \%)$ & $3(75 \%)$ & - & - & - & - \\
\hline & $\begin{array}{l}\text { Optometrician } \\
(\mathrm{n}=3)\end{array}$ & $1(33.33 \%)$ & $2(66.67 \%$ & & & & \\
\hline
\end{tabular}

Table 6: Practice of guidelines questions

\begin{tabular}{|c|c|c|c|c|c|c|c|}
\hline & \multicolumn{2}{|c|}{ Doctor $(n=60)$} & \multicolumn{2}{|c|}{ Nurse $(n=4)$} & \multicolumn{2}{|c|}{ Optometrist $(n=3)$} & \multirow{2}{*}{ P Value } \\
\hline & Yes & No & Yes & No & Yes & No & \\
\hline Qn1 & $60(100 \%)$ & - & $4(100 \%)$ & - & $3(100 \%)$ & - & \\
\hline Qn2 & $60(100 \%)$ & - & $4(100 \%)$ & - & $3(100 \%)$ & - & \\
\hline Qn3 & $60(100 \%)$ & - & $4(100 \%)$ & - & $3(100 \%)$ & - & \\
\hline Qn4 & $60(100 \%)$ & - & $4(100 \%)$ & - & $3(100 \%)$ & - & \\
\hline Qn 5 & $59(98.33 \%)$ & $11 .(67 \%)$ & $4(100 \%)$ & - & $3(100 \%)$ & - & 0.94 \\
\hline Qn 6 & $55(91.67 \%)$ & $5(8.33 \%)$ & $4(100 \%)$ & & $3(100 \%)$ & & 0.72 \\
\hline Qn 7 & $60(100 \%)$ & - & $4(100 \%)$ & - & $3(100 \%)$ & - & \\
\hline Qn 8 & $60(100 \%)$ & - & $4(100 \%)$ & - & $3(100 \%)$ & - & \\
\hline Qn 9 & $60(100 \%)$ & - & $4(100 \%)$ & - & $3(100 \%)$ & - & \\
\hline
\end{tabular}

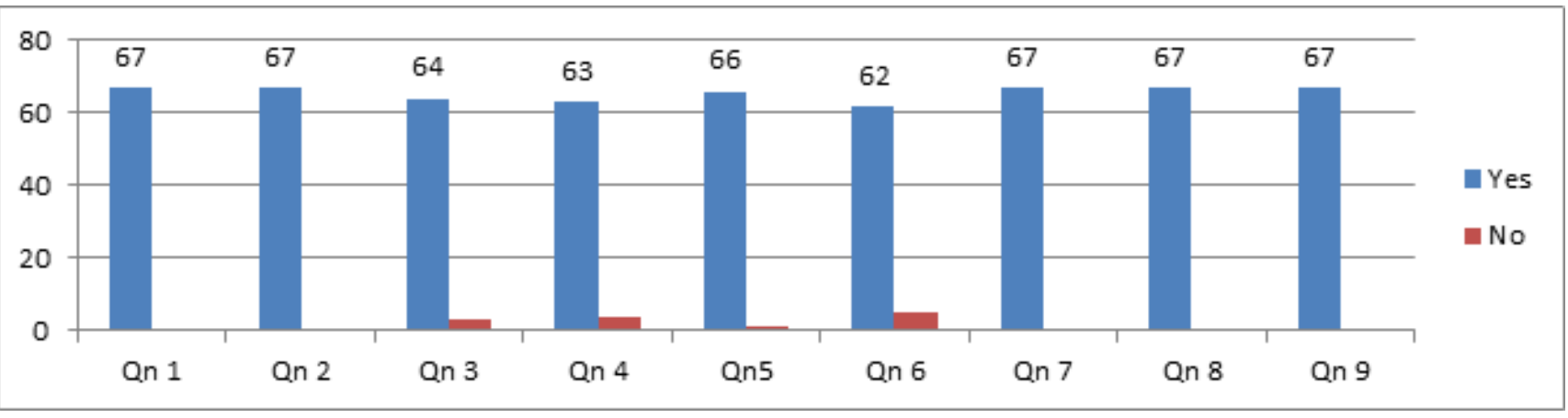

Fig. 2: Assessment of practice of guidelines for Novel Covid 19 
symptom of Covid-19. It is found that all the participants in the study are aware of the guidelines provided by the government of India this is in contrast to the findings of the study conducted in Nigeria. Knowledge regarding ophthalmic emergency guidelines laid by the government of India was found to be wrong among $n=10(16.67 \%)$ of doctors.

Based on the assessment of likert scale regarding the attitude of participants towards Covid-19, overall $72 \%$ of the participants strongly agree to question no 1,2,3,4,5,7(Figure 2). The optimistic attitude of the participants are similar to the study conducted in china. ${ }^{9}$ The tools we have to prevent the transmission of this virus is isolation and quarantine, social distancing, screening of general population which was strictly employed in a massive scale in China, ${ }^{8} \mathrm{n}=5(85 \%)$ of doctors, $n=4(100 \%)$ of nurses, $n=3(100 \%)$ of optometrists strongly agree to promote the use of Tele-counseling and Tele-consultation Which is similar to study Nigeria where the facility was increased but utilization was poor. The attitude towards the measures adopted by the ministry of health in our country was not very supportive among the participants as $\mathrm{n}=20(33.33 \%)$ of doctors, $\mathrm{n}=1(25 \%)$ of nurses, $n=1(33.33 \%)$ of the optometrists strongly agree towards it.

On assessing practice questionnaire most of the participants followed all the precautions necessary and issued by the government to combat the virus which is similar to the study conducted in Iran and China. ${ }^{9}$ from the study it was found that all the participants have received training in PPE during management of patient which is in contrast to the study conducted in Nigeria. Regarding the guidelines of CPWD(central public works department) for air-conditioning/ventilation, $\mathrm{n}=59(98.33 \%)$ of doctors, $100 \%$ of nurses, optometrist follow the guidelines. It was found that all the participants wear mask, maintain social distancing also follow proper disposal of mask/gloves/face covers.

This study helped in identifying knowledge gaps regarding guidelines issued by the government of India, the attitude differences and how the current situation of pandemic is managed by various practice methods by the health care professionals participated in the study.

\section{Limitations}

Among the study participants majority were doctors $(n=60)$ and the study was among only one section of health care professionals involved in the battle with Covid-19 i.e; the eye care professionals, hence the data obtained cannot be extrapolated to a wider section of health care professionals.

\section{Conclusion}

From this study it was found that majority of health care professionals had good knowledge, positive attitude and the guidelines were practiced adequately. The knowledge regarding the guidelines regarding ophthalmic emergency was not very satisfactory, also there was difference regarding attitude towards the measures adopted by the government of India to battle against Covid-19. From this study we can conclude that there is need of improvement regarding strategies and measures adopted especially in the current situation where the pandemic still continues with new mutant viruses.

\section{Source of Funding}

This research study was not funded by any funding agencies in the public, commercial, or any other sectors.

\section{Ethics Approval}

The study was approved by institutional ethics committee.

\section{Conflicts of Interest}

The authors declare no conflict of interest.

\section{Acknowledgement}

The authors acknowledge all the Eye care professionals who participated and co-operated with the study.

\section{References}

1. Ali MM, Dar QA, Kamal Z, Khan A. Eye in COVID-19: A Brief Review. Pak J Ophthalmol. 2020;36(3). doi:10.36351/pjo.v36i3.1040.

2. Ekpenyong B, Obinwanne CJ, Ovenseri-Ogbomo G, Ahaiwe K, Lewis OO, Echendu DC, et al. Assessment of Knowledge, Practice and Guidelines towards the Novel COVID-19 among Eye Care Practitioners in Nigeria-A Survey-Based Study. Int J Environ Res Public Health. 2020;17(14):5141. doi:10.3390/1jerph17145141.

3. Ciuca IM. COVID-19 in Children: An Ample Revie. Risk Manag Healthc Policy. 2020;13:661-9. do1:10.2147/rmhp.s257180.

4. Kumar SU, Kumar DT, Christopher BP, Doss CGP. The Rise and Impact of COVID-19 in India. Front Med. 2020;7:250. dol:10.3389/tmed202000250.

5. Al-Hanawi MK, Angawi K, Alshareef N, Qattan AMN, Helmy HZ, Abudawood Y, et al. Knowledge, Attitude and Practice Toward COVID19 Among the Public in the Kingdom of Saudi Arabia: A CrossSectional Study. Front Public. 2020;8:217.

6. Minocha A, Sim SY, Than J, Vakros G. Survey of ophthalmology practitioners in A\&E on current COVID-19 guidance at three Major UK Eye Hospitals. Eye. 2020;34:1243-5. 101:10.1038/s4/433-(020-085/-5.

7. Li JPO, Lam DSC, Chen Y, Ting DSW. Novel Coronavirus disease 2019 (COVID-19): The importance of recognising possible early ocular manifestation and using protective eyewear. $\mathrm{Br}$ J Ophthalmol. 2020;104:297-8.

8. Wilder-Smith A, Freedman DO. Isolation, quarantine, social distancing and community containment: pivotal role for old-style public health measures in the novel coronavirus (2019-nCoV) outbreak. J Travel Med. 2020;27(2). do1:10.1093/jtm/taaa020.

9. Zhong BL, Luo W, Li HM, Zhang QQ, Liu XG, Li WT. Knowledge, attitudes, and practices towards COVID-19 among chinese residents during the rapid rise period of the COVID-19 outbreak: A quick online cross-sectional survey. Int J Biol Sci. 2020;16(10):1745-52. 


\section{Author biography}

Aswathi Venugopal, Junior Resident

Sunil Kumar, HOD

Sony Sinha, Associate Professor
Cite this article: Venugopal A, Kumar S, Sinha S. Evaluation of

knowledge, attitude and practice of guidelines towards the novel covid

19 among eye care professionals of a government medical college in north India. Indian J Clin Exp Ophthalmol 2021;7(2):314-320. 